\title{
PtNi nanoparticles embedded in porous silica microspheres as highly active catalysts for $p$-nitrophenol hydrogenation to $p$-aminophenol
}

\author{
HUIJUAN GUAN, CONG CHAO, YANJIE LU, HUISHAN SHANG, YAFEI ZHAO, \\ SIGUO YUAN and BING ZHANG* \\ School of Chemical Engineering, Zhengzhou University, Zhengzhou 450001, P.R. China \\ e-mail: zhangb@zzu.edu.cn
}

MS received 28 June 2016; accepted 15 July 2016

\begin{abstract}
Supported Pt-based alloy nanoparticles have attracted greater attention in catalysis due to their high activity, reduced cost, and easy recycling in chemical reactions. In this work, mesoporous $\mathrm{SiO}_{2}$ microspheres were employed as support to immobilize PtNi alloy nanocatalysts with different mass ratios of Pt and $\mathrm{Ni}$ (1:0, 3:1, 1:1, 1:3 and 0:1) by a facile in situ one-step reduction in the absence of any capping agent. SEM, EDS, TEM, FTIR, XRD, ICP-AES, XPS and nitrogen adsorption/desorption analysis were employed to systematically investigate the morphology and structure of the obtained $\mathrm{SiO}_{2}$ microspheres and $\mathrm{SiO}_{2} / \mathrm{PtNi}$ nanocatalysts. Results show that uniform PtNi nanoparticles can be homogeneously and firmly embedded into the surface of $\mathrm{SiO}_{2}$ microspheres. When the as-prepared $\mathrm{SiO}_{2} / \mathrm{PtNi}$ nanocatalysts were used in the reduction process of $p$ nitrophenol to $p$-aminophenol, the nanocatalyst with Pt and Ni mass ratio of 1:3 showed the highest catalytic activity (TOF of $5.35 \times 10^{18}$ molecules $\cdot \mathrm{g}^{-1} \cdot \mathrm{s}^{-1}$ ) and could transform $p$-nitrophenol to $p$-aminophenol completely within $5 \mathrm{~min}$. The $\mathrm{SiO}_{2} / \mathrm{PtNi}$ nanocatalyst can also maintain high catalytic activity in the fourth cycle, implying its excellent stability during catalysis.
\end{abstract}

Keywords. Porous silica microsphere; Bimetallic alloy; PtNi; nanocatalysts; Hydrogenation reaction.

\section{Introduction}

p-Aminophenol, an important fine chemical, is widely used in the manufacturing industries, such as pharmaceuticals, dyestuffs, rubber antioxidants and other

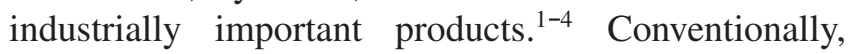
$p$-aminophenol is produced by multi-step iron-acid reduction of $p$-nitrochlorobenzene or $p$-nitrophenol, which causes severe environmental problems by generating a large amount of Fe-FeO sludge. ${ }^{5,6}$ To meet the growing demand of $p$-aminophenol, it is important to develop an efficient and green approach for the direct catalytic hydrogenation of $p$-nitrophenol. ${ }^{7,8}$ Recently, catalytic hydrogenation of $p$-nitrophenol into $p$-aminophenol by $\mathrm{NaBH}_{4}$ with addition of nanocatalysts has been widely considered as a safe and green process. ${ }^{9}$ A large variety of metal nanocatalysts including noble metals, transition metals and their alloys, have been explored for improving the efficiency of this reduction reaction. ${ }^{10-12}$ Among them, Pt-based alloys have aroused general concern thanks to their improved catalytic activity for many industrially important reactions, which is attributed to the synergetic effects of $\mathrm{Pt}$ and other metals, including geometric effect originated from the lattice contraction

*For correspondence and electronic effect caused by the downshift of the d-band center of $\mathrm{Pt}$ in the bimetallic structures. ${ }^{13-18}$ For example, Ghosh et al., reported that the catalytic activity of PtNi bimetallic nanoparticles is 15 times higher than that of monometallic Pt nanoparticles in the reduction of $p$-nitrophenol. ${ }^{19}$ Although bimetallic nanoparticles displayed excellent catalytic properties, their catalytic activities often dropped suddenly after the catalytic transformation because of the aggregation and leaching of the bimetallic catalysts.

Previous studies have revealed that immobilization of bimetallic nanocatalysts onto inorganic or organic supports can improve their stabilization and recycling ability to some extent, such as nanotube or nanofiber, inorganic microsphere and polymer textile and film. Commonly, nanocatalysts are usually attached on the outer surface of the supports due to easy preparation and exposure of active sites. ${ }^{20-22}$ However, they may be quickly consumed during repeated use due to weak binding, chemical erosion or excessive stripping. Encapsulation of nanocatalysts with core-shell structure was suggested to be an efficient approach to isolate the inner nanocatalyst core from the external environment, which can protect the inner nanocatalyst and effectively avoid their aggregation and loss during chemical reactions. However, the existence of shell structure on 
nanocatalysts may reduce the diffusivity and heat conductivity of the reaction system, resulting in a decrease in catalytic efficiency. ${ }^{23-25}$

Herein, we prepared porous $\mathrm{SiO}_{2}$ microspheres consisting of nanoparticles and employed them as support to immobilize PtNi alloy nanocatalysts by a one-step reduction approach which can not only enhance the binding force between nanoparticles and support, but also expose nanocatalysts directly to reactants without sacrificing catalytic activity. The as-prepared $\mathrm{SiO}_{2}$ microsphere-supported PtNi nanocatalysts show superior catalytic activity (TOF of $5.35 \times 10^{18}$ molecules $\cdot \mathrm{g}^{-1} \cdot \mathrm{s}^{-1}$ ) toward the reduction of $p$-nitrophenol to $p$-aminophenol, and they can also maintain very high activity in the fourth cycle, implying that the obtained $\mathrm{SiO}_{2} / \mathrm{PtNi}$ nanocatalysts possess both high activity and good stability.

\section{Experimental}

\subsection{Reagents and instruments}

Benzyl alcohol, methylcellulose, octaphenyl polyoxyethylene-10 (OP-10), polyethylene glycol 2000, hydrazine hydrate and $\mathrm{NaBH}_{4}$ were purchased from Tianjin Kemiou chemical reagent Co. Ltd., China; $p$-nitrophenol from Shanghai Macklin biochemical Co. Ltd., China; Absolute ethanol, ethylene glycol, $\mathrm{Ni}\left(\mathrm{NO}_{3}\right)_{2} \cdot 6 \mathrm{H}_{2} \mathrm{O}$ and $\mathrm{NaOH}$ from Tianjin Fengchuan chemical technology Co. Ltd.; $\mathrm{H}_{2} \mathrm{PtCl}_{6} \cdot 6 \mathrm{H}_{2} \mathrm{O}$ from Sinopharm chemical reagent Co. Ltd. Silica colloidal suspension (GRJ-30) was from Anyang Hongda Jingzhu material Co. Ltd. Double-distilled water was used throughout the experiment. Polyethylene glycol 2000 was chemically pure grade and all other reagents were of analytically pure grade and were used without further purification.

Nitrogen adsorption/desorption isotherms and the corresponding pore size distribution were recorded on Quantachrome NOVA4200 specific surface area and pore size distribution analyzer. Field emission scanning electron microscopy (FE-SEM) images were observed by JEOL JSM-6701F FE-SEM with an energy dispersive X-ray spectroscope (EDS). Transmission electron microscopy (TEM) images were taken using a JEOL JEM-2100 TEM. FTIR spectra were obtained on NICOLET NEXUS-470 FTIR spectrophotometer. XRay Powder Diffraction (XRD) data were obtained with a Rigaku Ultima III X-ray diffractometer. The compositions of the catalysts were determined using Shimadzu ICPS-7500 inductively coupled plasma-atomic emission spectrometry (ICP-AES) technique. Highresolution X-ray photoelectron spectroscopy (XPS) was carried out on a VG ESCALAB250 X-ray photoelectron spectrometer. The catalytic activities of the as-prepared catalysts were determined on UV-2450 $\mathrm{UV}$-Vis spectrophotometer.

\subsection{Preparation of mesoporous $\mathrm{SiO}_{2}$ microspheres}

The synthesis of mesoporous $\mathrm{SiO}_{2}$ microspheres was carried out by a microemulsion system involving benzyl alcohol, methylcellulose, OP-10, silica colloidal suspension and polyethylene glycol 2000. Benzyl alcohol $(20 \mathrm{~mL})$, methylcellulose (1.4 wt $\%, 1 \mathrm{~mL})$ and $\mathrm{OP}-10$ $(19 \mathrm{vt} \%, 1 \mathrm{~mL})$ were first mixed and stirred at $25^{\circ} \mathrm{C}$ for $10 \mathrm{~min}$. Then silica colloidal suspension $(6 \mathrm{~mL})$ and polyethylene glycol 2000 saturated aqueous solution (6 $\mathrm{mL}$ ) were added into the above mixture, and uniform surfactant stabilized W/O emulsion was formed with continuous stirring for $30 \mathrm{~min}$. After that, the emulsion was subjected to reduced pressure distillation at $60^{\circ} \mathrm{C}$ to remove water. The solid was separated by centrifugation followed by washing alternately with water and absolute ethanol, and then dried at $90^{\circ} \mathrm{C}$ for $24 \mathrm{~h}$. Finally, mesoporous $\mathrm{SiO}_{2}$ microspheres were obtained by calcination of the sample at $550^{\circ} \mathrm{C}$ for $2 \mathrm{~h}$.

\subsection{Preparation of $\mathrm{SiO}_{2}$-supported nanocatalysts}

$\mathrm{SiO}_{2} / \mathrm{PtNi}$ nanocatalysts were synthesized by a one-step chemical reduction method in the absence of capping agent. Taking $\mathrm{SiO}_{2} / \mathrm{PtNi}$ nanocatalyst with $\mathrm{Pt}$ and $\mathrm{Ni}$ mass ratio of 3:1 for example, mesoporous $\mathrm{SiO}_{2}$ microspheres $(35 \mathrm{mg}$ ) were added to ethylene glycol (80 $\mathrm{mL}$ ) and ultrasonicated for $1 \mathrm{~h}$ to form a stable suspension of $\mathrm{SiO}_{2}$ microspheres. $\mathrm{H}_{2} \mathrm{PtCl}_{6} \cdot 6 \mathrm{H}_{2} \mathrm{O}$ aqueous solution $(0.03352 \mathrm{~mol} / \mathrm{L}, 0.08 \mathrm{~mL})$ and $\mathrm{Ni}\left(\mathrm{NO}_{3}\right)_{2} \cdot 6 \mathrm{H}_{2} \mathrm{O}$ $(0.9 \mathrm{mg}$ ) (with initial mass ratio of $\mathrm{Pt}: \mathrm{Ni}=3: 1$ ) were dissolved in ethylene glycol $(20 \mathrm{~mL})$. Then, this metal salt solution was added to the above $\mathrm{SiO}_{2}$ suspension followed by addition of hydrazine hydrate ( $85 \mathrm{wt} \%, 0.8$ $\mathrm{mL})$ and $\mathrm{NaOH}$ ethylene glycol solution $(0.375 \mathrm{~mol} / \mathrm{L}$, $3.6 \mathrm{~mL}$ ), and this mixture was kept in an ultrasonic bath for $10 \mathrm{~min}$, and then heated at $110^{\circ} \mathrm{C}$ for $3 \mathrm{~h}$ under $\mathrm{N}_{2}$ atmosphere. Next, the above suspension was cooled and subsequently separated by centrifugation. The synthesized solid products were thoroughly washed with water and absolute ethanol, and then dried in a vacuum oven at $50^{\circ} \mathrm{C}$ for $24 \mathrm{~h}$ to obtain $\mathrm{SiO}_{2} / \mathrm{PtNi}$ (3:1) nanocatalyst with theoretical loading of $2 \mathrm{wt} \%$. For comparison, a series of $\mathrm{SiO}_{2} / \mathrm{PtNi}$ nanocatalysts with the same theoretical loading and different mass ratios of Pt and $\mathrm{Ni}(1: 0,1: 1,1: 3$ and $0: 1)$ were also prepared using the same method. 


\subsection{Catalytic and recycling experiments}

The reduction reaction of $p$-nitrophenol to $p$-aminophenol was adopted as a probe reaction to quantitatively evaluate the catalytic activity of the as-prepareed catalysts at $25^{\circ} \mathrm{C}$, and the process was monitored by UV-Vis absorption spectra. In a typical procedure, freshly prepared $p$-nitrophenol aqueous solution $\left(2 \times 10^{-3} \mathrm{~mol} / \mathrm{L}\right.$, $20 \mathrm{~mL})$ and $\mathrm{NaBH}_{4}$ aqueous solution $(0.25 \mathrm{~mol} / \mathrm{L}, 20$ $\mathrm{mL}$ ) were mixed to form a uniform solution by stirring for $10 \mathrm{~min}$, and then the prepared catalyst (15.0 $\mathrm{mg}$ ) were added into the above solution. During the reaction process, $0.5 \mathrm{~mL}$ of the reaction solution was taken from the reaction system at a regular interval of $1 \mathrm{~min}$, and subsequently diluted with double-distilled water $(9.5 \mathrm{~mL})$. The reaction processes were monitored by measuring the changing of UV-Vis absorbance of $p$-nitrophenol at $400 \mathrm{~nm}$. The sampling procedure was continued until the reaction solution became colorless. The reusability was tested by the same procedure using $\mathrm{SiO}_{2} / \mathrm{PtNi}(1: 3)$ nanocatalyst.

\section{Results and Discussion}

\subsection{Characterization of the as-synthesized target products}

The porous structure of the $\mathrm{SiO}_{2}$ microspheres was characterized by nitrogen adsorption/desorption analysis. $\mathrm{SiO}_{2}$ microspheres exhibit type-IV adsorption isotherm pattern with a hysteresis loop in the range of $\mathrm{P} / \mathrm{P}_{0}$ 0.4-0.9 (Figure 1a). According to the IUPAC classification, the shape of the hysteresis loop is identified as type-H1, corresponding to the cylindrical and narrow mesoporous pores within the $\mathrm{SiO}_{2}$ microspheres. ${ }^{26}$ The $\mathrm{SiO}_{2}$ microspheres have a specific BET surface area of $202.63 \mathrm{~m}^{2} / \mathrm{g}$ and average pore diameter of $3.84 \mathrm{~nm}$ (Figure 1b). The large surface area provides ample space for embedding of metal nanoparticles.

The morphology and surface microstructure of $\mathrm{SiO}_{2}$ microspheres and metal-loaded $\mathrm{SiO}_{2}$ microspheres were examined by FE-SEM operated at $15 \mathrm{kV}$ in high vacuum. In Figure 2a, it can be seen that spherical $\mathrm{SiO}_{2}$ with the diameter of about 5-20 $\mu \mathrm{m}$ were obtained. The microspheres are formed by numberous nanoparticles with diameter of 5-15 nm, and the particle stacking endows the microspheres with porous structure (Figure 2b), which is beneficial to the loading of metal particles by embedding them among the nanoparticles. By comparing the surfaces of microspheres and metalloaded microspheres at low magnification (Figures 2a and $2 \mathrm{c}$ ), it is found that there are no significant differences on the surfaces, meaning that the metal loading process does not change the overall morphology of $\mathrm{SiO}_{2}$ support. However, the SEM image of the metalloaded microspheres at high magnification shows that there are a large number of bright particles on the surface (Figure 2d), which reveals that metal nanoparticles are successfully loaded on the surface of $\mathrm{SiO}_{2}$ mesoporous microspheres. The loaded metal nanoparticles are uniformly distributed with diameter varying from 20 to $45 \mathrm{~nm}$. A closer examination further reveals that most nanoparticles are embedded into mesoporous microspheres, which can effectively avoid the loss of catalysts and thus improve the catalyst stability (Figure 2d). In addition, the EDS spectrum of metalloaded $\mathrm{SiO}_{2}$ microspheres further confirm that the elements of Pt and Ni can be homogenously distributed in the $\mathrm{SiO}_{2}$ matrix (Figures 2e and 2f).

Figure 3 a shows the TEM image of $\mathrm{SiO}_{2}$-supported PtNi nanocatalysts, the image further confirms the successful loading of metal nanoparticles on mesoporous $\mathrm{SiO}_{2}$ microspheres. As shown in HRTEM in Figure 3b,
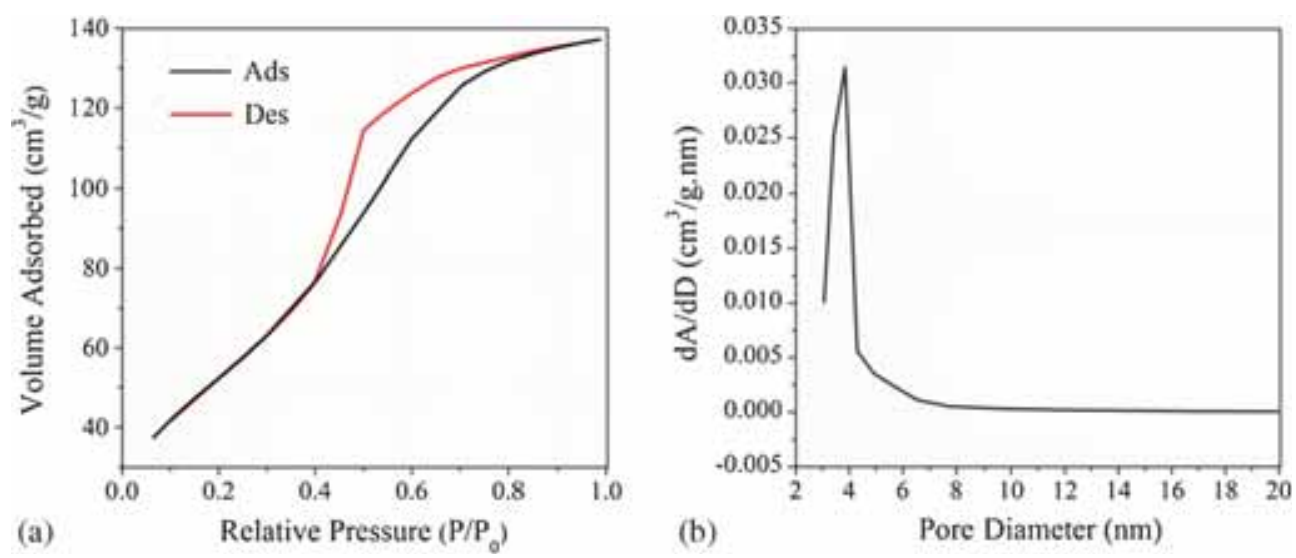

Figure 1. (a) Nitrogen adsorption/desorption isotherms and (b) the corresponding pore size distribution of $\mathrm{SiO}_{2}$ microspheres. 

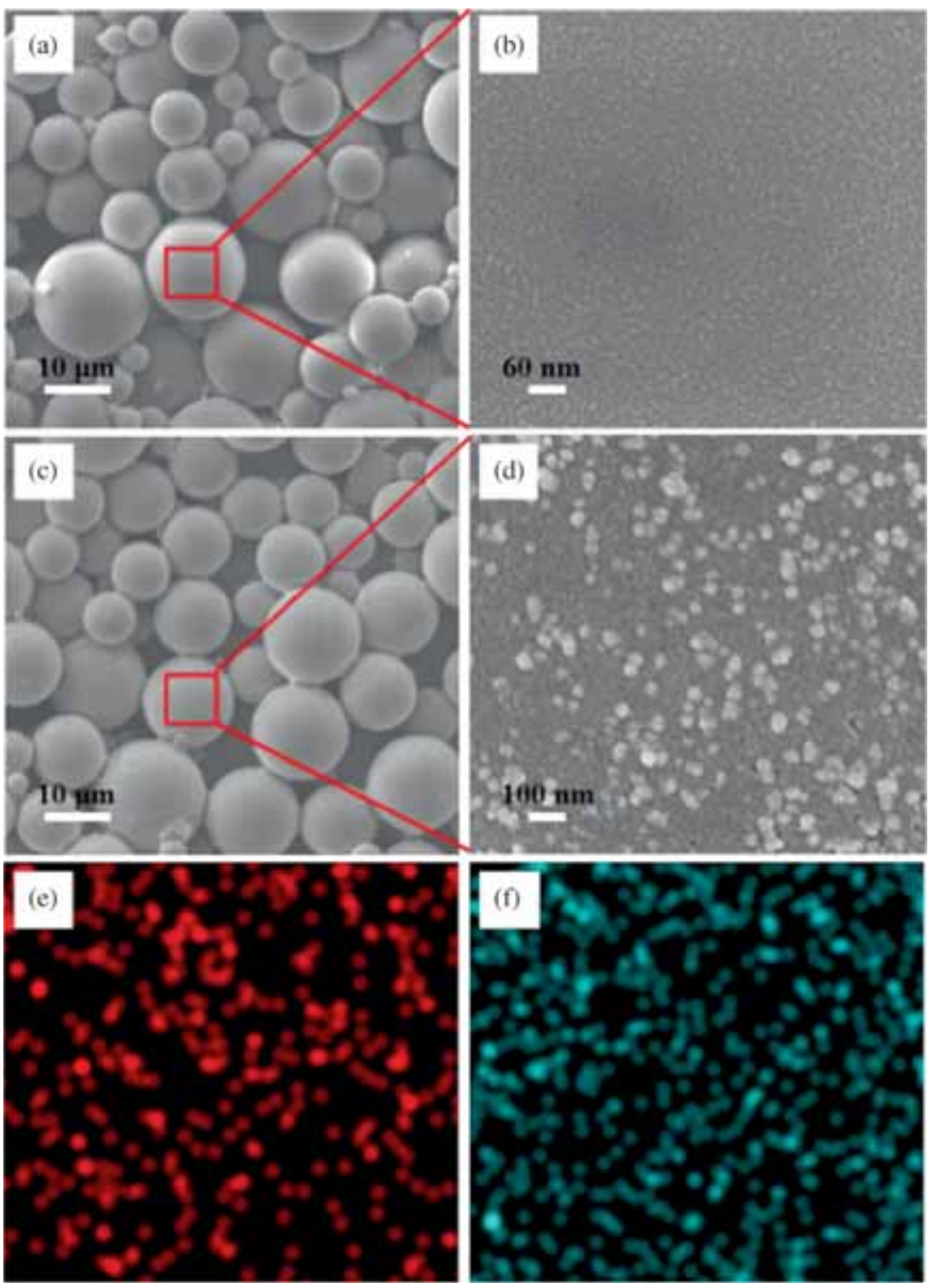

Figure 2. SEM images of $\mathrm{SiO}_{2}$ microspheres: (a) before and (c) after loading metals. The enlarged SEM images of $\mathrm{SiO}_{2}$ microspheres surface: (b) before and (d) after loading metals. EDS elemental mapping images of (e) Pt and (f) Ni distributed in $\mathrm{SiO}_{2}$ microspheres.

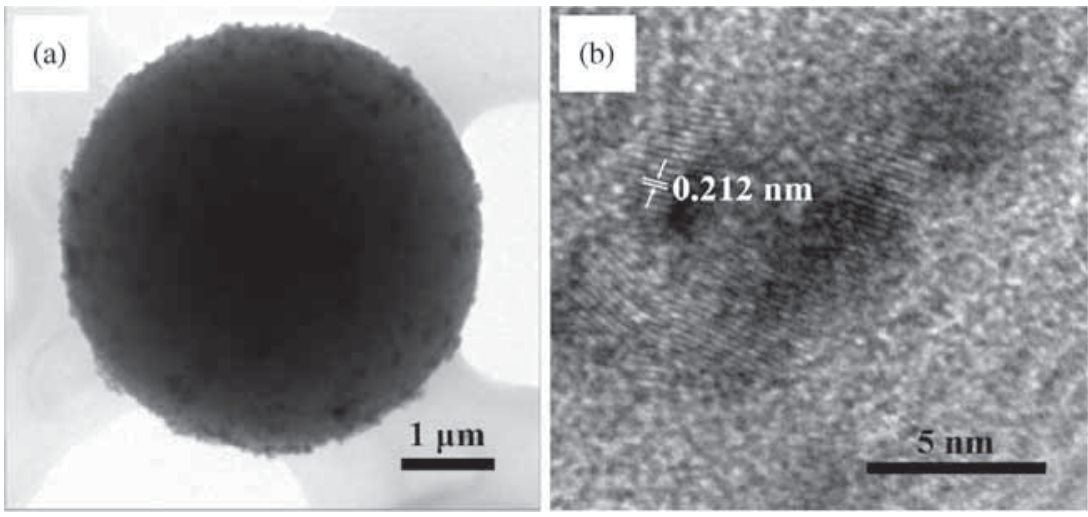

Figure 3. TEM and HRTEM images of $\mathrm{SiO}_{2}$-supported PtNi nanocatalysts. 
the lattice spacing of $0.212 \mathrm{~nm}$ is smaller than that of the (111) plane of $\mathrm{Pt}(0.23 \mathrm{~nm})$ and larger than that of pure $\mathrm{Ni}(0.203 \mathrm{~nm})$, suggesting that PtNi alloy is formed. This result agrees well with the previous report by Sahoo. ${ }^{27}$ The lattice fringes correspond to (111) plane of the face-centered cubic (fcc) PtNi alloy. ${ }^{28}$

Figure 4 shows the comparison of the FTIR spectra of $\mathrm{SiO}_{2}$ and $\mathrm{SiO}_{2}$-supported nanocatalysts. For the
$\mathrm{SiO}_{2}$ microsphere, the peaks at about 3457 and $1635 \mathrm{~cm}^{-1}$ belong to the $\mathrm{O}-\mathrm{H}$ vibration of $\mathrm{SiO}_{2}$. The absorption around 1113, 793 and $470 \mathrm{~cm}^{-1}$ can be attributed to the asymmetric stretching mode, symmetric stretching mode and bending vibration of $\mathrm{Si}-\mathrm{O}-\mathrm{Si}$, respectively (Figure 4a). $\mathrm{SiO}_{2}$-supported nanocatalysts maintain all the characteristic bands of $\mathrm{SiO}_{2}$ without obvious new absorption appearing in the FTIR spectra
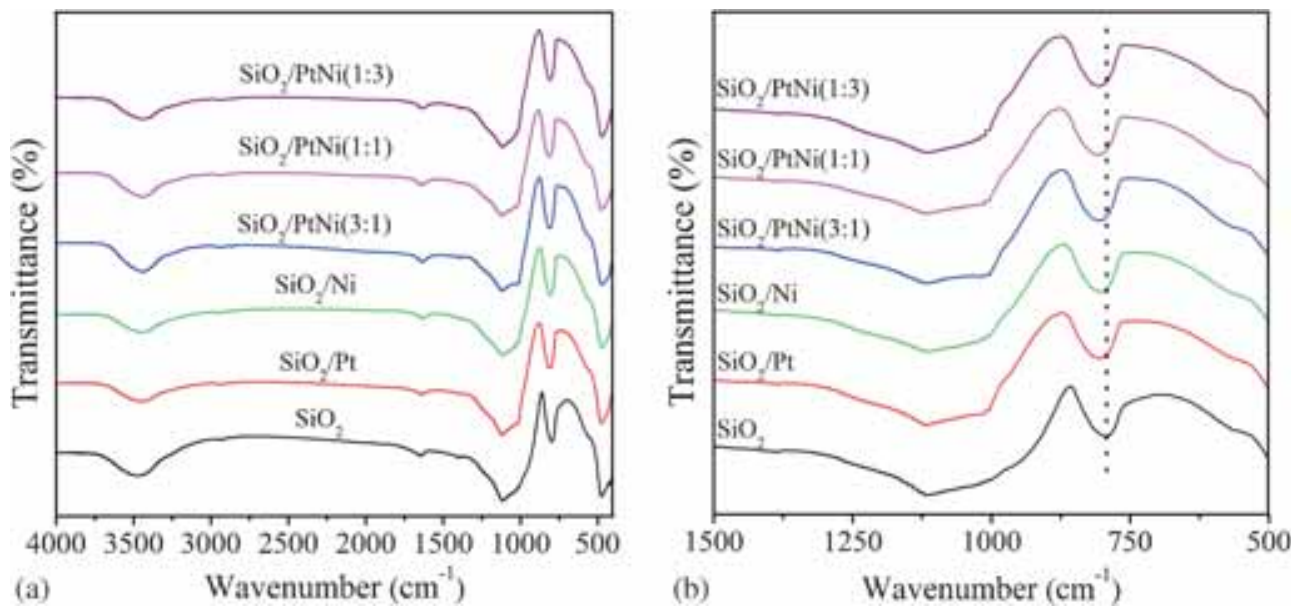

Figure 4. (a) The comparison of the FTIR spectra between $\mathrm{SiO}_{2}$ and $\mathrm{SiO}_{2}$-supported nanocatalysts. (b) Partial enlarged FTIR spectra of $\mathrm{SiO}_{2}$ and $\mathrm{SiO}_{2}$-supported nanocatalysts.
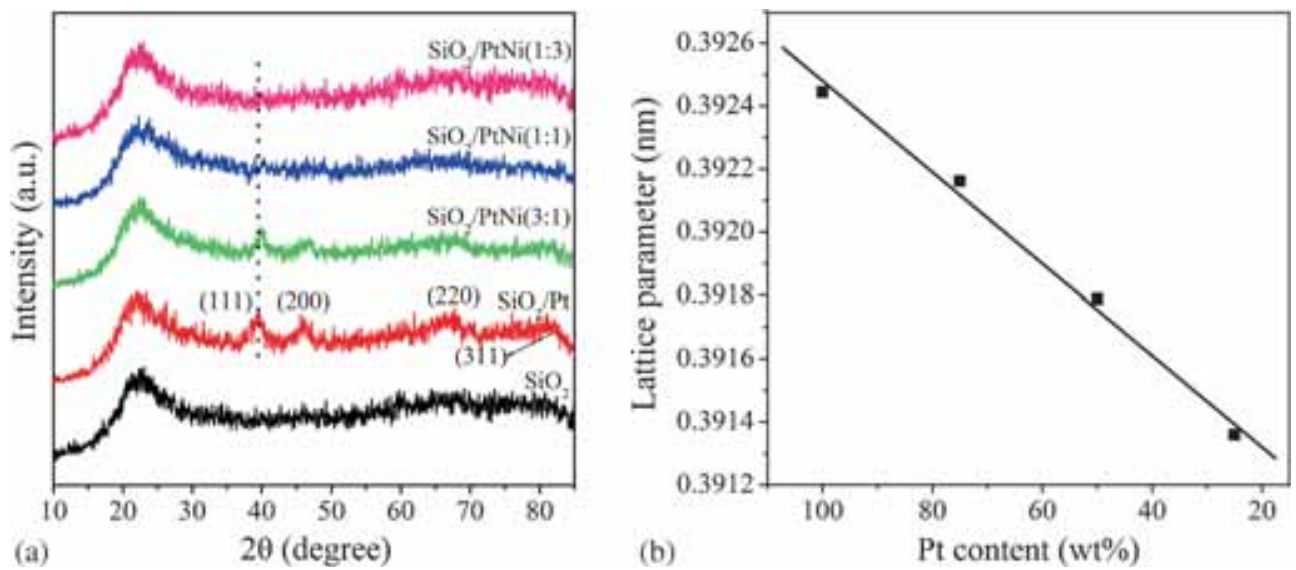

Figure 5. (a) XRD patterns of $\mathrm{SiO}_{2}$ and $\mathrm{SiO}_{2}$-supported nanocatalysts. (b) Lattice parameters of $\mathrm{Pt}$ in $\mathrm{SiO}_{2} / \mathrm{PtNi}$ nanocatalysts with different mass ratios of $\mathrm{Pt}$ and $\mathrm{Ni}$ (1:0, 3:1, 1:1 and $1: 3$ ) deduced from XRD.

Table 1. ICP-AES results of catalysts with different mass ratios.

\begin{tabular}{lcccc}
\hline Catalysts & Pt loading (wt\%) & Ni loading (wt\%) & Pt+Ni loading (wt\%) & Pt/Ni mass ratio \\
\hline $\mathrm{SiO}_{2} / \mathrm{Pt}$ & $1.61 \%$ & - & $1.61 \%$ & $100: 0$ \\
$\mathrm{SiO}_{2} / \mathrm{PtNi}(3: 1)$ & $1.21 \%$ & $0.40 \%$ & $1.61 \%$ & $75.2: 24.8$ \\
$\mathrm{SiO}_{2} / \mathrm{PtNi}(1: 1)$ & $0.76 \%$ & $0.81 \%$ & $1.57 \%$ & $48.4: 51.6$ \\
$\mathrm{SiO}_{2} / \mathrm{PtNi}(1: 3)$ & $0.39 \%$ & $1.26 \%$ & $1.65 \%$ & $23.6: 76.4$ \\
$\mathrm{SiO}_{2} / \mathrm{Ni}$ & - & $1.70 \%$ & $1.70 \%$ & $0: 100$ \\
\hline
\end{tabular}


(Figure 4a). However, observing from the enlarged FTIR spectra between $1500 \mathrm{~cm}^{-1}$ and $500 \mathrm{~cm}^{-1}$ in Figure $4 \mathrm{~b}$, it is found that the symmetric $\mathrm{Si}-\mathrm{O}-\mathrm{Si}$ stretching modes of the $\mathrm{SiO}_{2}$-supported nanocatalyst are slightly shifted to higher wavenumber values compared with that of pure $\mathrm{SiO}_{2}$, which can be attributed to the loading of metals. ${ }^{29,30}$

Figure 5a shows the XRD patterns of $\mathrm{SiO}_{2}$ and $\mathrm{SiO}_{2}$ supported nanocatalysts. A broad diffraction peak of $\mathrm{SiO}_{2}$ at 2 theta in the range of $20-30^{\circ}$ correspond to the amorphous $\mathrm{SiO}_{2}$ (JCPDS 29-0085). ${ }^{31}$ For the $\mathrm{SiO}_{2} / \mathrm{Pt}$ nanocatalyst, there are four diffraction peaks detected at around $39.8,46.2,67.5$ and $81.3^{\circ}$, which are attributed

Table 2. Electronegativities of single metals and calculated effective electronegativities of PtNi bimetals.

\begin{tabular}{lccccc}
\hline Metals & $\mathrm{Pt}$ & $\mathrm{Ni}$ & $\mathrm{PtNi}(3: 1)$ & $\mathrm{PtNi}(1: 1)$ & $\operatorname{PtNi}(1: 3)$ \\
\hline$\chi_{\text {effective }}$ & 2.28 & 1.91 & 2.09 & 1.99 & 1.94 \\
\hline
\end{tabular}
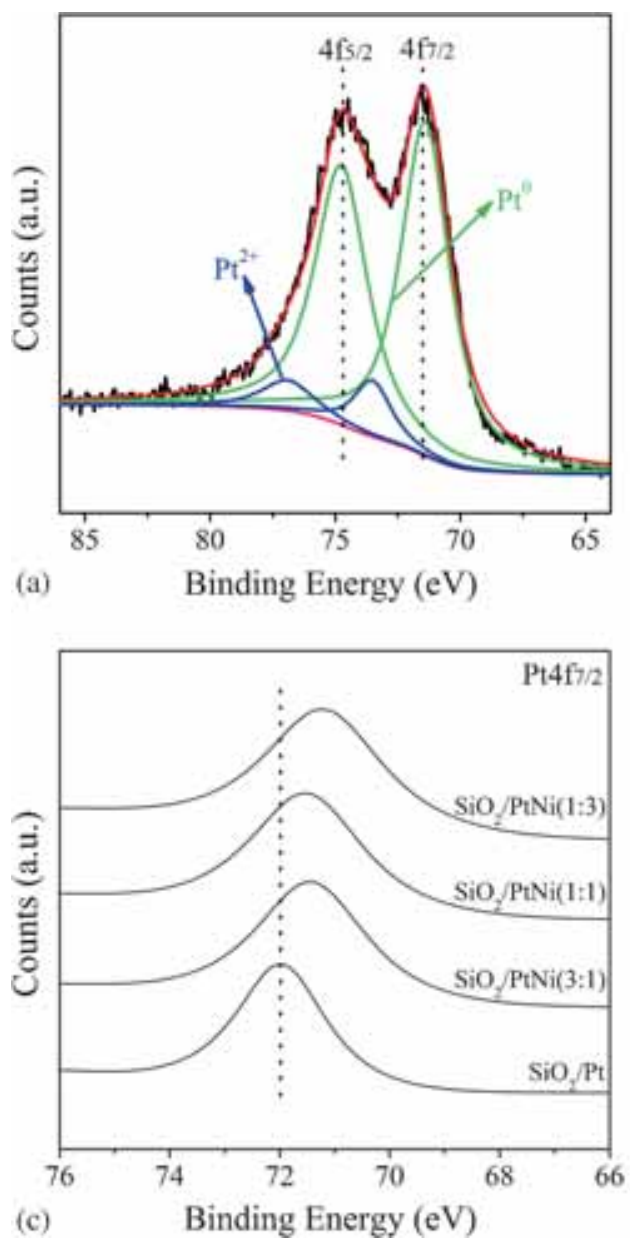

to the (111), (200), (220) and (311) crystal planes of Pt fcc crystal structure (JCPDS 04-0802), respectively. Diffraction patterns of the $\mathrm{SiO}_{2} / \mathrm{PtNi}$ nanocatalysts show similar peaks as those of $\mathrm{SiO}_{2} / \mathrm{Pt}$ nanocatalyst, and the peaks of $\mathrm{Pt}$ gradually weakened with the decrease of Pt content. It's worth noting that the Pt (111) diffraction peaks of $\mathrm{SiO}_{2} / \mathrm{PtNi}$ nanocatalysts are slightly shifted to higher 2 theta values with respect to $\mathrm{SiO}_{2} / \mathrm{Pt}$ nanocatalyst, and this minor shift in XRD peak position indicates that $\mathrm{Ni}$ atoms have gone into the $\mathrm{Pt}$ lattice and formed substitution solid solution with $\mathrm{Pt}^{32}$ The narrowing of peak (111) of Pt with the increase of $\mathrm{Ni}$ content suggests that the lattice parameter of $\mathrm{Pt}$ is decreased by occupying the lattice site of Pt with $\mathrm{Ni}^{33}$ The lattice parameter of Pt deduced from XRD by software of Jade 6 shows a linear decrease with the decrease of $\mathrm{Pt}$ content in $\mathrm{SiO}_{2} / \mathrm{PtNi}$ nanocatalyst (Figure $5 \mathrm{~b}$ ), which is also indicative of the formation of $\mathrm{PtNi}$ alloy.

The actual loading amounts of $\mathrm{Pt}$ and $\mathrm{Ni}$ in the $\mathrm{SiO}_{2}-$ supported nanocatalysts with different mass ratios were analyzed by ICP-AES, and the results are shown in
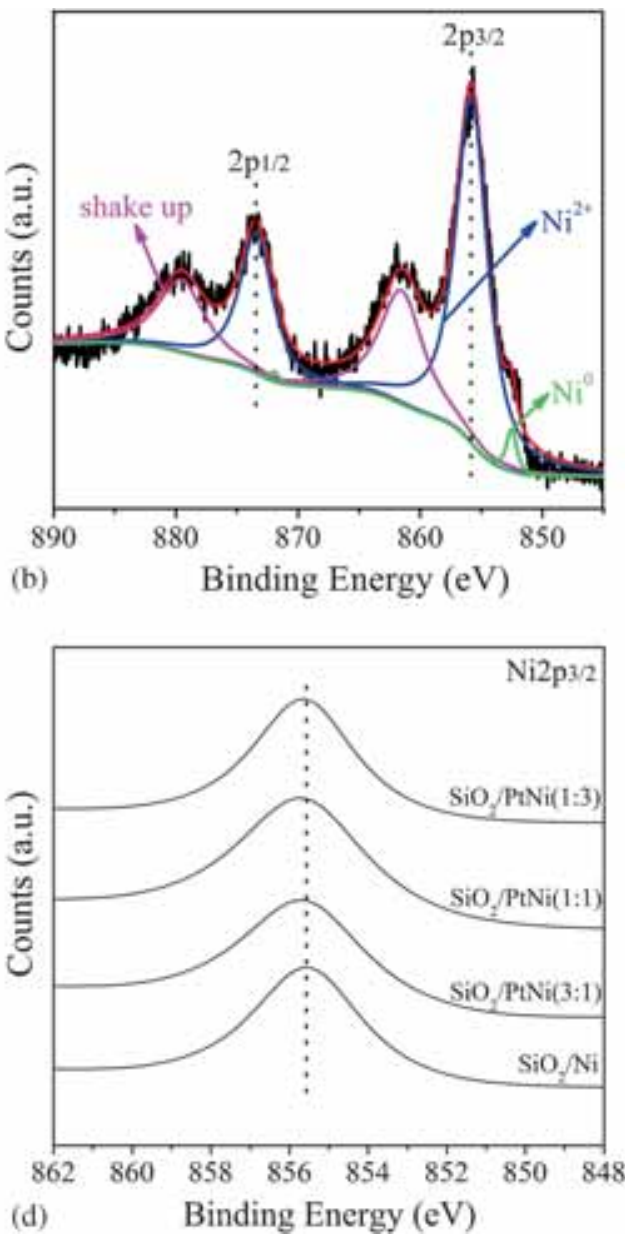

(d)

Figure 6. The XPS spectra of, (a) Pt4f in the $\mathrm{SiO}_{2} / \mathrm{PtNi}(3: 1)$ nanocatalyst; (b) Ni2p in the $\mathrm{SiO}_{2} / \mathrm{PtNi}(1: 3)$ nanocatalyst; (c) The $\mathrm{Pt} 4 \mathrm{f}_{7 / 2}$ peaks of $\mathrm{SiO}_{2} / \mathrm{Pt}$ and $\mathrm{SiO}_{2} / \mathrm{PtNi}$ nanocatalysts; (d) The $\mathrm{Ni} 2 \mathrm{p}_{3 / 2}$ peaks of $\mathrm{SiO}_{2} / \mathrm{Ni}$ and $\mathrm{SiO}_{2} / \mathrm{PtNi}$ nanocatalysts. 

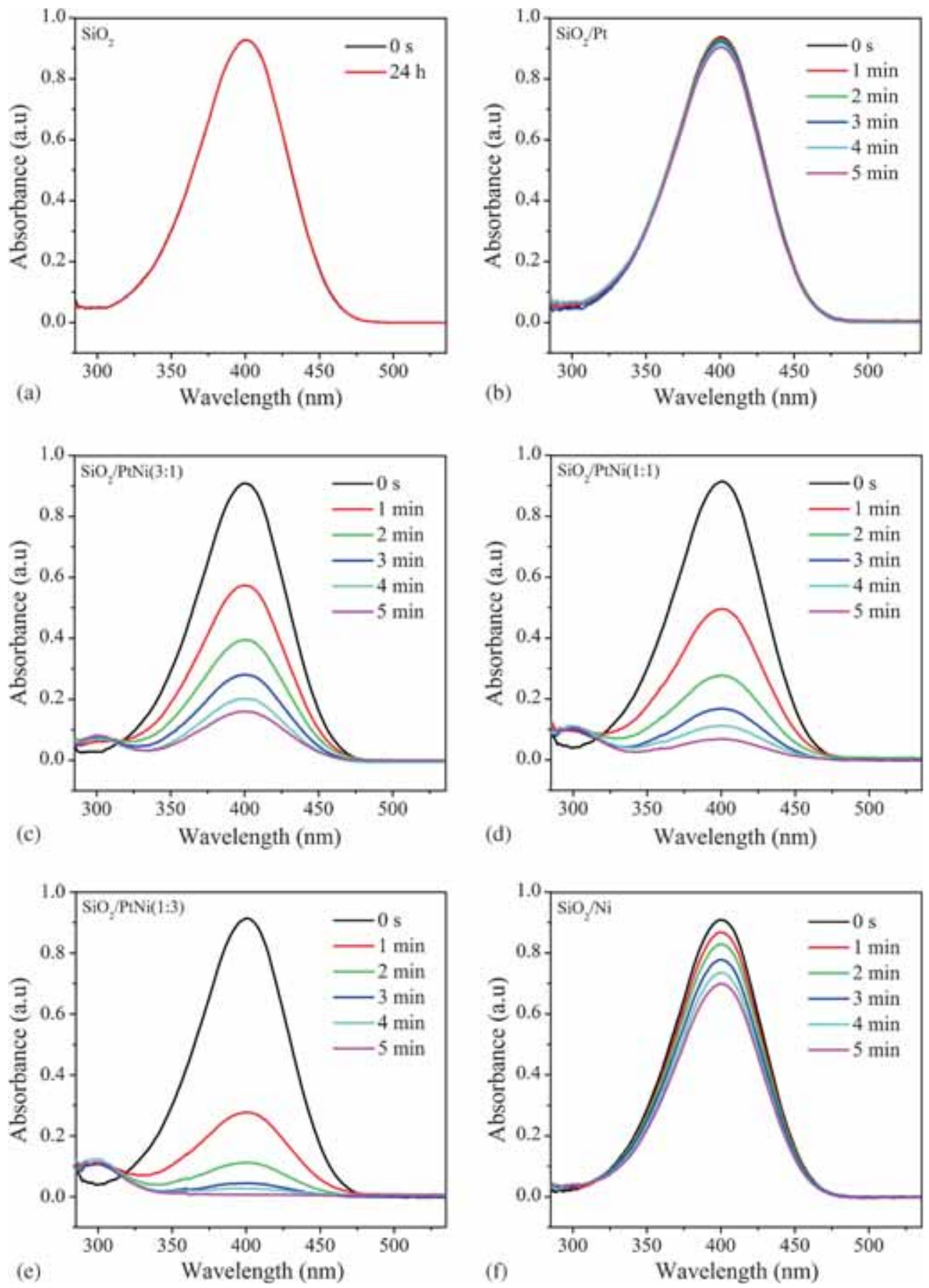

Figure 7. Time-dependent UV-Vis absorption spectral changes of $p$-nitrophenol catalyzed by different catalysts.

Table 1. It is found that the amounts of $\mathrm{Pt}, \mathrm{Ni}$ and $\mathrm{PtNi}(\mathrm{Pt}+\mathrm{Ni})$ on the $\mathrm{SiO}_{2}$ microspheres varied from $1.57 \%$ to $1.70 \%$ and they are all close to the theoretical loading amount of $2 \mathrm{wt} \%$, implying most of metal ion precursors are reduced to metals and loaded on $\mathrm{SiO}_{2}$ surface. Besides, the actual mass ratios of $\mathrm{Pt}$ and $\mathrm{Ni}$ are all approximate to the theoretical mass ratios. Thus, the theoretical mass ratios are adopted in the following description for convenience.
Li et al., proposed a new concept for bi- or multimetallics, that is, effective electronegativity $\left(\chi_{\text {effective }}\right)$, and concluded that only alloys whose effective electronegativity is greater than or equal to a critical value (1.93) can indeed be prepared. ${ }^{34} \chi_{\text {effective }}$ is determined by the electronegativity of the component metals and the value is given by the following equation:

$$
\chi_{\text {effective }}\left(M_{x} M_{y}^{\prime}\right)=\frac{x}{x+y} \chi_{M}+\frac{y}{x+y} \chi_{M^{\prime}}
$$


where $\mathbf{M}$ and $\mathbf{M}^{\prime}$ are different metal elements in the alloy, respectively. $\mathrm{x}$ and $\mathrm{y}$ represent the atom number of $\mathrm{M}$ and $\mathrm{M}^{\prime}$, respectively. $\chi_{\mathrm{M}}$ and $\chi_{\mathrm{M}^{\prime}}$ are the electronegativity of $\mathrm{M}$ and $\mathrm{M}^{\prime}$, respectively.

Based on the above formula and ICP-AES results, the $\chi_{\text {effective }}$ values of PtNi nanocatalysts were calculated and summarized in Table 2. It can be seen that the $\chi_{\text {effective }}$ values of PtNi nanocatalysts are all larger than 1.93, implying the possibility of synthesizing PtNi alloy nanocatalysts with the given composition.

The XPS measurement was used to evaluate the surface structures and chemical states of the $\mathrm{SiO}_{2}$ supported nanocatalysts. Figures $6 \mathrm{a}$ and $6 \mathrm{~b}$ show the XPS spectra of $\mathrm{Pt} 4 \mathrm{f}$ in the $\mathrm{SiO}_{2} / \mathrm{PtNi}$ (3:1) nanocatalyst and $\mathrm{Ni} 2 \mathrm{p}$ in the $\mathrm{SiO}_{2} / \mathrm{PtNi}(1: 3)$ nanocatalyst, respectively. It can be observed that Pt exists predominantly in $\mathrm{Pt}$ form, and the binding energies of $\mathrm{Pt} 4 \mathrm{f}\left(4 \mathrm{f}_{7 / 2}=71.36\right.$ $\left.\mathrm{eV}, 4 \mathrm{f}_{5 / 2}=74.76 \mathrm{eV}\right)$ are close to the standard values of bulk Pt $\left(4 \mathrm{f}_{7 / 2}=70.90 \mathrm{eV}, 4 \mathrm{f}_{5 / 2}=74.25 \mathrm{eV}\right)$, demonstrating that $\mathrm{Pt}^{4+}$ precursor is successfully reduced to form metallic $\mathrm{Pt}$ on the $\mathrm{SiO}_{2}$ surface (Figure 6a). In the fine spectra of $\mathrm{Ni} 2 \mathrm{p}$ (Figure 6b), the peaks of $855.64 \mathrm{eV}$ and $873.76 \mathrm{eV}$ are assigned to $\mathrm{Ni}^{2+} 2 \mathrm{p}_{3 / 2}$ and $\mathrm{Ni}^{2+} 2 \mathrm{p}_{1 / 2}$, and the binding energies of $852.52 \mathrm{eV}$ and $871.94 \mathrm{eV}$ are ascribed to $\mathrm{Ni} 2 \mathrm{p}_{3 / 2}$ and $\mathrm{Ni} 2 \mathrm{p}_{1 / 2}$, respectively, suggesting that the dominant surface phases for $\mathrm{Ni}$ are oxidized species. ${ }^{35}$ Besides, there are two satellite signals at $861.88 \mathrm{eV}$ and $879.63 \mathrm{eV}$ adjacent to the main peaks of $\mathrm{Ni}$, which may be ascribed to multielectron excitation (shake-up peaks). ${ }^{36}$ The $\mathrm{Pt} 4 \mathrm{f}_{7 / 2}$ peaks of $\mathrm{SiO}_{2} / \mathrm{PtNi}$ nanocatalysts show slight negative shifts compared to that of $\mathrm{SiO}_{2} / \mathrm{Pt}$ nanocatalyst (Figure $6 \mathrm{c}$ ), while the $\mathrm{Ni} 2 \mathrm{p}_{3 / 2}$ peaks show positive shifts compared to that of $\mathrm{SiO}_{2} / \mathrm{Ni}$ nanocatalyst (Figure 6d), which may be caused by the transfer of electrons from $\mathrm{Ni}$ to $\mathrm{Pt}$ in PtNi alloy. ${ }^{37,38} \mathrm{In}$ addition, it is also observed that the $\mathrm{Pt}_{4} \mathrm{f}_{7 / 2}$ peaks for $\mathrm{SiO}_{2} / \mathrm{PtNi}$ nanocatalysts are all broader than that of $\mathrm{SiO}_{2} / \mathrm{Pt}$ nanocatalyst, and the width of $\mathrm{Pt}_{4} \mathrm{f}_{7 / 2}$ increases with increasing $\mathrm{Ni}$ concentration in $\mathrm{PtNi}$ alloy, which may result from the overlap of the Ni3p peak with the $\mathrm{Pt}_{4 / 2} \mathrm{f}_{7 / 21}$

\subsection{Catalytic properties and reusability of the as-prepared catalysts}

The reduction reaction of $p$-nitrophenol to $p$-aminophenol was adopted as a probe reaction to quantitatively evaluate the catalytic activity of the as-prepared catalysts. The absorbance of $p$-nitrophenol was determined with a UV-Vis spectrophotometer at the maximum wavelength of $400 \mathrm{~nm}^{42,43}$ The time-dependent UV-Vis adsorption spectra changes of $p$-nitrophenol catalyzed by different catalysts are compared in Figure 7 .
The conversion rates $(\%)$ of $p$-nitrophenol to $p$-aminophenol at $5 \mathrm{~min}$ for $\mathrm{SiO}_{2} / \mathrm{Pt}, \mathrm{SiO}_{2} / \mathrm{Ni}, \mathrm{SiO}_{2} / \mathrm{PtNi}(3: 1)$, $\mathrm{SiO}_{2} / \mathrm{PtNi}(1: 1)$ and $\mathrm{SiO}_{2} / \mathrm{PtNi}(1: 3)$ nanocatalysts are $3.6,21.5,82.4,92.5$ and $100.0 \%$, respectively. It is observed that no reduction reaction occurred in the presence of pure $\mathrm{SiO}_{2}$, even after $24 \mathrm{~h}$ of experimentation (Figure 7a), indicating that $\mathrm{SiO}_{2}$ microsphere itself cannot be used as catalyst and this reduction reaction cannot proceed without catalyst The result is in good accordance with the previous report by Sahoo. ${ }^{27}$ Notably, $\mathrm{SiO}_{2} / \mathrm{Pt}$ nanocatalyst shows low catalytic activity, the reaction almost did not occur in $5 \mathrm{~min}$ (Figure 7b). However, the catalytic activities of $\mathrm{SiO}_{2} / \mathrm{PtNi}$ nanocatalysts are greatly improved with the increase of $\mathrm{Ni}$ content. Among these $\mathrm{SiO}_{2} / \mathrm{PtNi}$ nanocatalysts $\mathrm{SiO}_{2} / \mathrm{PtNi}(1: 3)$ nanocatalyst showed the highest activity and transformed $p$-nitrophenol to $p$-aminophenol completely within 5 min (Figure 7(c-e)). Furthermore, the absorbance peak of $p$-aminophenol at $300 \mathrm{~nm}$ appeared and its intensity increased with reaction time, indicating the conversion of $p$-nitrophenol to $p$-aminophenol. ${ }^{44}$ Compared with $\mathrm{SiO}_{2} / \mathrm{PtNi}$ nanocatalysts, $\mathrm{SiO}_{2} / \mathrm{Ni}$ nanocatalyst shows a slower catalytic activity (Figure 7f), which reveals that bimetallic nanocatalysts have better catalytic properties than monometallic nanocatalysts. Moreover, the catalytic experiment for the physical mixture of $\mathrm{SiO}_{2} / \mathrm{Pt}$ and $\mathrm{SiO}_{2} / \mathrm{Ni}$ (with mass ratio of $\mathrm{SiO}_{2} / \mathrm{Pt}: \mathrm{SiO}_{2} / \mathrm{Ni}=1: 3$ ) was conducted in order to compare with the catalytic activity of $\mathrm{SiO}_{2} / \mathrm{PtNi}$ nanocatalysts. The results suggest that $\mathrm{SiO}_{2} / \mathrm{PtNi}$ nanocatalysts show much higher catalytic activity than that of the physical mixture of $\mathrm{SiO}_{2} / \mathrm{Pt}$ and $\mathrm{SiO}_{2} / \mathrm{Ni}$ (Figure $\mathrm{S} 1$ in Supplementary Information).

The kinetics of this reduction reaction was studied with different catalysts. It usually followed the

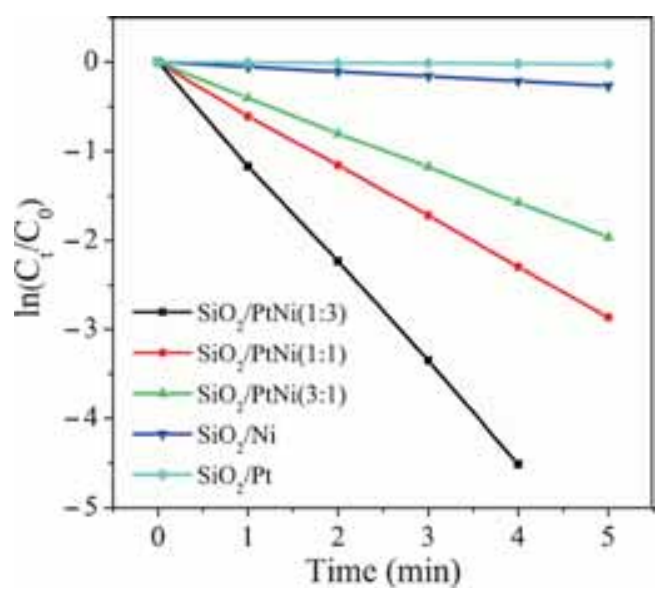

Figure 8. Plots of $\ln \left(C_{\mathrm{t}} / C_{0}\right)$ versus time in the presence of different catalysts. 
pseudo-first-order kinetics with respect to the concentration of $p$-nitrophenol, ${ }^{45,46}$ as follows:

$$
\ln \left(C_{t} / C_{0}\right)=\ln \left(A_{t} / A_{0}\right)=-k t
$$

where $C_{\mathrm{t}}$ and $C_{0}$ represent the concentrations of $p$ nitrophenol at times $t$ and $t=0$, respectively $A_{\mathrm{t}}$ and $A_{0}$ are the absorbances of $p$-nitrophenol (at peak of $400 \mathrm{~nm}$ ) at times $\mathrm{t}$ and $\mathrm{t}=0$, respectively $k$ is the rate constant.

Figure 8 shows the plots of $\ln \left(C_{\mathrm{t}} / C_{0}\right)$ vs time in the presence of different catalysts. The $\ln \left(C_{\mathrm{t}} / C_{0}\right)$ shows a good linear correlation $\left(R^{2}>0.999\right)$ with the reaction time for all catalysts, confirming the agreement with pseudo-first-order kinetics. Turnover frequency (TOF) is an important factor for evaluating the efficiency of catalysts In the heterogeneous catalysis, TOF is the number of reactant molecules that $1 \mathrm{~g}$ of catalyst can convert into products in unit time. ${ }^{47,48} \mathrm{TOF}$ of this reduction reaction can be calculated by using $0.4 \mathrm{mmol}$ of $p$-nitrophenol and $15 \mathrm{mg}$ of catalysts. The $k$ obtained from the slopes of the linearly fitted plots of $\ln \left(C_{\mathrm{t}} / C_{0}\right)$ vs time and TOF values of different catalysts are given in Table 3. It is obvious that the catalytic activities of the catalysts follow the order of $\mathrm{SiO}_{2} / \mathrm{Pt}<\mathrm{SiO}_{2} / \mathrm{Ni}$ $<\mathrm{SiO}_{2} / \mathrm{PtNi}(3: 1)<\mathrm{SiO}_{2} / \mathrm{PtNi}(1: 1)<\mathrm{SiO}_{2} / \mathrm{PtNi}(1: 3)$. The catalytic activities of $\mathrm{SiO}_{2} / \mathrm{PtNi}$ nanocatalysts are higher than those of $\mathrm{SiO}_{2} / \mathrm{Pt}$ and $\mathrm{SiO}_{2} / \mathrm{Ni}$ nanocatalysts. The improvement of catalytic activities can be attributed to electronic effect (downshift of the dband center on PtNi alloy) and geometric effect (the unique structures of PtNi alloys), which can facilitate

Table 3. The $k$ and TOF values for the reduction of $p$-nitrophenol with different catalysts and the correlation coeffcients for $\ln \left(C_{\mathrm{t}} / C_{0}\right)$ vs time plots.

\begin{tabular}{lccccc}
\hline Catalysts & $\mathrm{SiO}_{2} / \mathrm{Pt}$ & $\mathrm{SiO}_{2} / \mathrm{Ni}$ & $\mathrm{SiO}_{2} / \mathrm{PtNi}(3: 1)$ & $\mathrm{SiO}_{2} / \mathrm{PtNi}(1: 1)$ & $\mathrm{SiO}_{2} / \mathrm{PtNi}(1: 3)$ \\
\hline$k\left(\mathrm{~min}^{-1}\right)$ & 0.0044 & 0.0525 & 0.3933 & 0.5743 & 1.1214 \\
$\mathrm{R}^{2}$ & 0.9999 & 0.9999 & 0.9999 & 0.9998 & 0.9998 \\
TOF $\left(\times 10^{18}\right)$ molecules $\cdot \mathrm{g}^{-1} \cdot \mathrm{s}^{-1}$ & 0.19 & 1.15 & 4.41 & 4.95 & 5.35 \\
\hline
\end{tabular}

Table 4. The comparison of $k$ and $\mathrm{TOF}$ of $\mathrm{SiO}_{2} / \mathrm{PtNi}(1: 3)$ with those of other catalysts reported in the literature for $p$-nitrophenol hydrogenation to $p$-aminophenol.

\begin{tabular}{lcccc}
\hline Catalysts & $C_{(p \text {-nitrophenol })} / \mathrm{mM}$ & $k / \mathrm{min}^{-1}$ & $\mathrm{TOF}\left(\times 10^{18}\right)$ molecules $\cdot \mathrm{g}^{-1} \cdot \mathrm{s}^{-1}$ & References \\
\hline $\mathrm{SiO}_{2} / \mathrm{PtNi}(1: 3)$ & 1.000 & 1.1214 & 5.35 & This work \\
$\mathrm{RGO} / \mathrm{PtNi}(25: 75)$ & 0.096 & 0.0672 & 0.96 & 27 \\
PtNi nanosnowflakes/RGO & 0.091 & 0.1302 & - & 9 \\
Pt-Au ANCs & 0.007 & 0.0800 & - & 27 \\
PtNi(25:75) & 0.096 & 0.0173 & 0.45 & 27 \\
\hline
\end{tabular}

$C_{(p \text {-nitrophenol })}:$ the initial concentration of $p$-nitrophenol.
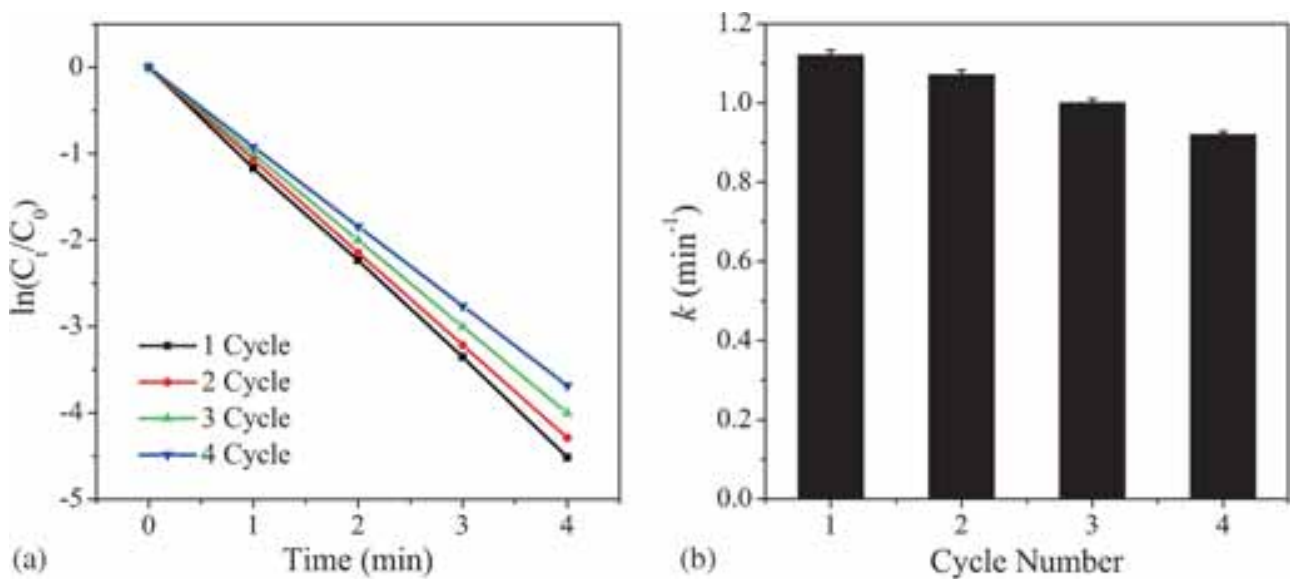

Figure 9. (a) The plots of $\ln \left(C_{\mathrm{t}} / C_{0}\right)$ vs time and (b) the values of $k$ for each cycle with $\mathrm{SiO}_{2} / \mathrm{PtNi}(1: 3)$ nanocatalyst as catalyst. 
the relaying of electrons to $p$-nitrophenol from borohydride ions and endow more activity sites available for the adsorption of reactant molecules. ${ }^{9,49,50}$ In addition, PtNi embedded into the surface of mesoporous microspheres, which can expose nanocatalysts directly to the reactants and increase its catalytic efficiency correspondingly.

To further demonstrate the superior catalytic performance of $\mathrm{SiO}_{2} / \mathrm{PtNi}(1: 3)$ nanocatalyst, comparison of $k$ and TOF between the as-prepared nanocatalyst and the catalysts reported in the literature are given in Table 4. The $k$ of $1.1214 \mathrm{~min}^{-1}$ and TOF of $5.35 \times 10^{18}$ molecules $\cdot \mathrm{g}^{-1} \cdot \mathrm{s}^{-1}$ of $\mathrm{SiO}_{2} / \mathrm{PtNi}(1: 3)$ nanocatalyst for the reduction of $p$-nitrophenol to $p$-aminophenol are much higher than those reported in the literature. ., $^{9,51}$ The higher catalytic efficiency may due to the effective loading and uniform dispersion of PtNi nanoparticles on $\mathrm{SiO}_{2}$ support.

Catalytic stability is an important characteristic for practical applications of nanocatalysts. ${ }^{52,53}$ In order to evaluate the catalytic stability of $\mathrm{SiO}_{2} / \mathrm{PtNi}$ nanocatalysts, the representative sample of $\mathrm{SiO}_{2} / \mathrm{PtNi}(1: 3)$ nanocatalyst was tested for reusability in the reduction of $p$-nitrophenol by $\mathrm{NaBH}_{4}$ for several cycles. The plots of $\ln \left(C_{\mathrm{t}} / C_{0}\right)$ vs time and the values of $k$ for each cycle are shown in Figure 9. It can be seen that the $k$ values slightly decrease with the increase in the number of cycles, and the errors are less than $1 \%$. It still can keep $82.08 \%$ of the $k$ value of original catalyst in the fourth cycle, which is much more stable than that in the previous report where the rate constant for the bare PtNi nanocatalyst drops drastically (about 50\%) in the second cycle. ${ }^{27}$ These results confirm that embedding PtNi alloy nanoparticles into $\mathrm{SiO}_{2}$ microspheres can improve the catalytic stability of nanocatalysts.

\section{Conclusions}

In summary, the nanocatalyst $\mathrm{PtNi}$ nanoparticles with uniform size can be homogeneously and firmly embedded into the surface of $\mathrm{SiO}_{2}$ microspheres to form $\mathrm{SiO}_{2} / \mathrm{PtNi}$ nanocatalysts. When the as-prepared nanocatalysts were used in the reduction process of $p$-nitrophenol to $p$-aminophenol, the $\mathrm{SiO}_{2} / \mathrm{PtNi}(1: 3)$ nanocatalyst showed superior catalytic activity (TOF of $5.35 \times 10^{18}$ molecules $\left.\cdot \mathrm{g}^{-1} \cdot \mathrm{s}^{-1}\right)$ and could transform $p$ nitrophenol to $p$-aminophenol completely within $5 \mathrm{~min}$. The $\mathrm{SiO}_{2} / \mathrm{PtNi}$ nanocatalyst can also maintain high catalytic activity in the fourth cycle. The results indicate that the $\mathrm{SiO}_{2} / \mathrm{PtNi}$ composite can be used as an effective and reusable catalyst for practical applications.

\section{Supplementary Information (SI)}

Additional information pertaining to the time-dependent UV-Vis adsorption spectra changes of $p$-nitrophenol catalyzed by physically mixed $\mathrm{SiO}_{2} / \mathrm{Pt}$ and $\mathrm{SiO}_{2} / \mathrm{Ni}$ are given in Figure S1, available at www.ias.ac.in/chemsci.

\section{Acknowledgements}

This work was supported by the National Natural Science Foundation of China (No. 21576247 and 21271158).

\section{References}

1. Du Y, Chen H, Chen R and Xu N 2004 Appl. Catal. A-Gen. 277259

2. Saha S, Pal A, Kundu S, Basu S and Pal T 2010 Langmuir 262885

3. Mandlimath T R and Gopal B 2011 J. Mol. Catal. A-Chem. 3509

4. Wu K, Wei X, Zhou X, Wu D, Liu X, Ye Y and Wang Q 2011 J. Phys. Chem. C 11516268

5. Lu H, Yin H, Liu Y, Jiang $\mathrm{T}$ and Yu L 2008 Catal. Commun. 10313

6. Rode C V, Vaidya M J and Chaudhari R V 1999 Org. Process Res. Dev. 3465

7. Vaidya M J, Kulkarni S M and Chaudhari R V 2003 Org. Process Res. Dev. 7202

8. Zhang Z, Xiao F, Xi J, Sun T, Xiao S, Wang H, Wang S and Liu Y 2014 Sci. Rep. 44053

9. Song P, Feng J, Zhong S, Huang S, Chen J and Wang A 2015 RSC Adv. 535551

10. Toshima N and Wang Y 1994 Langmuir 104574

11. Lu Z, Yin H, Wang A, Hu J, Xue W, Yin H and Liu S 2015 J. Ind. Eng. Chem. 22258

12. Hostetler M J, Wingate J E, Zhong C J, Harris J E, Vachet R W, Clark M R, Londono J D, Green S J, Stokes J J, Wignall G D, Glish G L, Porter M D, Evans N D and Murray R W 1998 Langmuir 1417

13. Ananthan S A, Suresh R, Giribabu K and Narayanan V 2013 J. Chem. Sci. 1251365

14. Kim J G, Im J K, Ryoo K K, Jeon J Y, Yoo S J and Kim S S 2015 J. Ind. Eng. Chem. 22258

15. Jeena S E and Selvaraju T 2016 J. Chem. Sci. 128357

16. Shukla A K, Raman R K, Choudhury N A, Priolkar K R, Sarode P R, Emura S and Kumashiro R 2004 J. Electroanal. Chem. 563181

17. Ghosh S and Raj C R 2015 J. Chem. Sci. 127949

18. Stamenkovic V R, Mun B S, Arenz M, Mayrhofer K J J, Lucas C A, Wang G, Ross P N and Markovic N M 2007 Nature Mater. 6241

19. Ghosh S 2004 Appl. Catal. A-Gen. 26861

20. Dogan Ü, Kaya M, Cihaner A and Volkan M 2012 Electrochim. Acta $\mathbf{8 5} 220$

21. Luo B, Xu S, Yan X and Xue Q 2012 Electrochem. Сотти. 2372

22. Wang M, Shen T, Wang M, Zhang D and Chen J 2013 Mater. Lett. 107311

23. Seo M, Kim S, Lee D W, Jeong H E and Lee K Y 2016 Appl. Catal. A Gen. $\mathbf{5 1 1} 87$

24. Shet A and Vidya S K 2016 Sol. Energy 12767 
25. Zhang H, Liu J, Tian Z, Ye Y, Cai Y, Liang C and Terabe K 2016 Carbon 100590

26. Leofanti G, Padovan M, Tozzola G and Venturelli B 1998 Catal. Today 41207

27. Sahoo P K, Panigrahy B and Bahadur D 2014 RSC Adv. 448563

28. Zhu E, Li Y, Chiu C, Huang X, Li M, Zhao Z, Liu Y, Duan X and Huang Y 2016 Nano Res. 9149

29. Considine D M 1983 In Van Nostrand's Scientific Encyclopedia (New York: John Wiley)

30. Williams D H and Fleming I 1987 In Spectroscopic methods in organic chemistry (New York: McGrawHill)

31. Si Y and Samulski E T 2008 Chem. Mater. 206792

32. Yang H, Vogel W, Lamy C and Alonsovante N 2004 J. Phys. Chem. 10811024

33. Souza L K C D, Zamian J R, Filho G N D R, Soledade L E B, Santos I M G D, Souza A G, Scheller T, Angélica R S and Costa C E F D 2009 Dyes Pigm. 81187

34. Wang D, Peng Q and Li Y 2010 Nano. Res. 3574

35. Lan M, Fan G, Wang Y, Yang L and Li F 2014 J. Mater. Chem. A 214682

36. Luo B, Xu S, Yan X and Xue Q 2013 J. Electrochem. Soc. 160 F262

37. Deng Y, Tian N, Zhou Z, Huang R, Liu Z, Xiao J and Sun S 2012 Chem. Sci. 31157

38. Yamauchi Y, Tonegawa A, Komatsu M, Wang H, Wang L, Nemoto Y, Suzuki N and Kuroda K 2012 J. Am. Chem. Soc. 1345100
39. Haber J A, Cai Y, Jung S, Xiang C, Mitrovic S, Jin J, Bell A T and Gregoire J M 2014 Energ. Environ. Sci. 7682

40. Haniff M A S M, Lee H W, Bien D C S and Azid I A 2014 J. Nanopart. Res. 161

41. Wakisaka M, Mitsui S, Hirose Y, Kawashima K, Uchida $\mathrm{H}$ and Watanabe M 2006 J. Phys. Chem. B 110 23489

42. Praharaj S, Nath S, Ghosh S K, Kundu S and Pal T 2004 Langmuir 209889

43. Zeng J, Zhang Q, Chen J and Xia Y 2010 Nano. Lett. 1030

44. Rashid M H, Bhattacharjee R R, Kotal A and Mandal T K 2006 Langmuir 227141

45. Lee J, Park J C, Bang J U and Song H 2008 Chem. Mater. 205839

46. Lee J, Park J C and Song H 2008 Adv. Mater. 201523

47. Saha S, Pal A, Kundu S, Basu S and Pal T 2010 Langmuir 262885

48. Saha S, Pal A, Pande S, Sarkar S, Panigrahi S and Pal T 2009 J. Phys. Chem. C 1137553

49. Raula M, Rashid M H, Lai S, Roy M and Mandal T K 2012 ACS Appl. Mater. Interfaces 4878

50. Yang J, Shen X, Ji Z, Zhou H, Zhu G and Chen K 2014 Appl. Surf. Sci. 316575

51. Fu G, Ding L, Chen Y, Lin J, Tang Y and Lu T 2014 CrystEngComm 161606

52. Jana D, Dandapat A and De G 2010 Langmuir 2612177

53. Lin F and Doong R 2011 J. Phys. Chem. C 1156591 